\title{
BMJ Carers' perspectives on the presentation OPen of community-acquired pneumonia and empyema in children: a case series
}

\author{
Joanna C Crocker, ${ }^{1}$ Meirion R Evans, ${ }^{1}$ Christopher C Butler, ${ }^{1}$ Kerenza Hood, ${ }^{1,3}$ \\ Colin V E Powell ${ }^{2}$
}

To cite: Crocker JC,

Evans MR, Butler CC, et al. Carers' perspectives on the presentation of communityacquired pneumonia and empyema in children: a case series. BMJ Open 2012;2: e001500. doi:10.1136/ bmjopen-2012-001500

- Prepublication history and additional material for this paper are available online. To view these files please visit the journal online (http://dx.doi.org/10.1136/ bmjopen-2012-001500)

Received 16 May 2012 Accepted 20 July 2012

This final article is available for use under the terms of the Creative Commons Attribution Non-Commercial 2.0 Licence; see http://bmjopen.bmj.com

${ }^{1}$ Institute of Primary Care and Public Health, School of Medicine, Cardiff University, Cardiff, UK

${ }^{2}$ Department of Child Health, School of Medicine, Cardiff University, Cardiff, UK ${ }^{3}$ South East Wales Trials Unit, School of Medicine, Cardiff University, Cardiff, UK

\section{Correspondence to} Dr Colin V E Powell, powellc7@cf.ac.uk

\section{ABSTRACT}

Objective: To describe carers' perceptions of the development and presentation of community-acquired pneumonia or empyema in their children.

Design: Case series.

Setting: Seven hospitals with paediatric inpatient units in South Wales, UK.

Participants: Carers of 79 children aged 6 months to 16 years assessed in hospital between October 2008 and September 2009 with radiographic, communityacquired pneumonia or empyema.

Methods: Carers were recruited in hospital and participated in a structured face-to-face or telephone interview about the history and presenting features of their children's illnesses. Responses to open questions were initially coded very finely and then grouped into common themes. Cases were classified into two age groups: 3 or more years and under 3 years.

Results: The reported median duration of illness from onset until the index hospital presentation was 4 days (IQR 2-9 days). Pain in the torso was reported in $84 \%$ of cases aged 3 or more years and was the most common cause for carer concern in this age group. According to carer accounts, clinicians sometimes misjudged the origin of this pain. Almost all carers reported something unusual about the index illness that had particularly concerned them-mostly nonspecific physical symptoms and behavioural changes.

Conclusions: Pain in the torso and carer concerns about unusual symptoms in their child may provide valuable additional information in a clinician's assessment of the risk of pneumonia in primary care. Further research is needed to confirm the diagnostic value of these features.

\section{INTRODUCTION}

Community-acquired pneumonia is an important cause of morbidity in children in the developed world, with about $10-15$ cases and 1-4 hospital admissions per 1000 children per year. ${ }^{1}$ Empyema is the most common complication, occurring in around $5 \%$ of hospitalised cases, ${ }^{2}{ }^{3}$ and appears to have increased in the UK and other

\section{ARTICLE SUMMARY}

Article focus

- Community-acquired pneumonia is often difficult to diagnose clinically, especially early in the disease process.

- Parental report that 'this illness is different from previous illnesses' has been identified as a red flag for serious infection in primary care.

- We describe the symptoms of a series of children who presented to hospital with pneumonia or empyema, from the perspective of their carers.

\section{Key messages}

- Pain in the torso (including the abdomen, back, shoulder and side) was a common symptom of pneumonia in children aged 3 or more years in our case series.

- Nearly all carers were worried by something unusual about the illness, mostly non-specific symptoms such as high fever or behavioural changes.

- Carers' reports of pain in the torso and/or symptoms different from previous illnesses may alert clinicians to consider pneumonia or empyema.

Strengths and limitations of this study

- Cases were recruited from seven hospitals in urban and rural locations.

- Data were collected directly from carers rather than from second-hand medical notes.

- Our case series is likely to be skewed towards more severe pneumonia, and data were gathered retrospectively, possibly leading to recall bias.

developed countries during the 1990s and early 2000s. ${ }^{4-11}$ Clinicians could play a role in the prevention of empyema by early diagnosis of pneumonia, but this is often a challenge as some children do not present with classical signs such as adventitious sounds on auscultation, tachypnoea and cough. ${ }^{12}{ }^{13} \mathrm{~A}$ confidential enquiry into child deaths in the UK implicated failure of general practitioners (GPs) to recognise and manage severe infection in the deaths of 11 children, 
including four due to pneumonia and one due to empyema with septicaemia. ${ }^{14}$ Such reports highlight the need to improve clinicians' ability to recognise serious infections such as pneumonia and empyema in primary care. Buntinx et al $l^{15}$ have articulated the dilemma GPs face in identifying such infections: 'Failure to shoulder any diagnostic risk overloads the health system and subjects patients to unnecessary worry and investigation. But accepting too much risk leads to missed cases, late diagnosis, and sometimes avoidable death.'

The UK National Audit of Paediatric Pneumonia ${ }^{2}$ and studies in other developed countries ${ }^{12} 1316$ have focused mainly on symptoms and signs recorded by clinicians rather than the illness history reported by carers. Blacklock et $a l^{17}$ recently concluded that parent-reported symptoms agreed poorly with nurse assessment and were unreliable discriminators of serious respiratory infection in children with suspected acute infection in a UK paediatric assessment unit. In contrast, a prospective study of serious infections (including pneumonia) in children presenting in primary care in Belgium identified the carer's statement that this illness was different from previous illnesses as a red flag for serious infection. ${ }^{18} 19$ However, the symptoms or signs responsible for this perceived difference were not investigated. Chest pain and abdominal pain have been reported in association with paediatric pneumonia, ${ }^{12}{ }^{16}$ but the frequency of referred pain at other sites, such as the back and shoulder, is largely unknown. Blacklock et $a l^{17}$ did not specifically investigate pain in the chest, back, side or shoulder, nor whether carers had expressed concern that their child's illness was different from previous illnesses.

We analysed data from a hospital-based case series in order to describe the symptoms of childhood pneumonia and empyema from the carer's perspective, with a focus on pain and unusual symptoms of particular concern.

\section{METHODS}

\section{Definition of cases}

Cases were children aged 6 months to 16 years assessed in hospital and given a diagnosis of clinical or radiographic community-acquired pneumonia or empyema by any treating clinician. Children were excluded if they had a serious underlying medical condition (including cystic fibrosis, severe immune deficiencies, cerebral palsy, diabetes mellitus, chronic renal failure, serious congenital or acquired heart disease and chronic lung disease of prematurity requiring home oxygen), if no chest radiograph was taken or if the carer(s) did not speak a sufficient level of English for informed consent. Participants were subsequently excluded from analysis if the radiologist's report did not describe the presence of at least one of the following features confirming radiographic pneumonia: consolidation, opacification, infiltrate, air bronchogram, air space shadowing, pneumonia or pleural effusion. Participants were also excluded from analysis if the principal discharge diagnosis was not consistent with pneumonia (eg, bronchiolitis).

\section{RECRUITMENT METHODS}

Between October 2008 and September 2009, cases were recruited from paediatric wards and assessment units in seven hospitals in South Wales (six district general hospitals and the Children's Hospital for Wales, Cardiff, which have a combined catchment population of approximately 2000000 ). Hospital clinicians gave carers a participation pack which included a detailed information sheet, consent form, questionnaire and freepost return envelope. Carers wishing to take part were asked to complete the consent form and questionnaire and return it to the researchers. Children aged over 12 years were also asked to provide assent.

\section{Data collection}

Demographic data and basic information about the index illness (eg, the date of illness onset) were collected from carers by a self-complete questionnaire on recruitment. Detailed information about the index illness was subsequently collected in an interview with the carer by a member of the research team (JCC). The interview included a series of open and closed questions about symptom history (box 1). Questions about pain (box 1-item 3) were only asked of children aged 3 years and over. Carers were interviewed face-to-face in hospital or by telephone as soon as possible after discharge from hospital. The questionnaire and interview schedule had been piloted with a convenience sample of non-medical carers and amended accordingly before use in the study. Carers' responses to closed questions, and all key words and phrases used in responses to open questions, were hand-recorded by the interviewer on a standardised form, along with field notes relevant to the

Box 1 Chronological list of interview questions about symptom history

1. 'Could you please tell me what you noticed when your child's illness first began?'

2. 'Did you notice any changes later?'

3. Series of closed questions about the presence or absence of 31 specific symptoms, for example, 'Did your child have a cough?' and 'Did your child have rapid, shallow breathing or panting?' Carers of children aged over 3 years were asked about complaints of pain in the torso (chest, tummy, back, sides, shoulders), headache and general aching

4. Series of supplementary questions about the timing of cough, pain in the torso and rapid breathing in the chronology of the illness, if present, for example, 'When did you first notice the cough?'

5. 'Was there anything unusual about this illness that particularly concerned you?' (Prompt: 'compared to previous illnesses your child has had?') 
study aims. For quality assessment purposes, 12 interviews $(15 \%)$ were audiotaped with the carers' permission (nine in the first 3 months of interviews and three in the last month of interviews). Medical data, including the radiologist's report and discharge diagnosis, were collected retrospectively from hospital records by a researcher (JCC) and three research nurses (AR, AH and MW) using a standardised form.

\section{Data analysis}

$\chi^{2}$ tests (for categorical variables) and Mann-Whitney $\mathrm{U}$ tests (for non-parametric continuous variables) were used for bivariate comparisons. Cases were classified into two age groups based on their ability to express pain and bodily sensations: 3 or more years and under 3 years. Responses to open questions were initially coded very finely and then grouped into common themes agreed by the research team, for example, fever or feverish symptoms, cough, 'cold', ears, throat, pain in the torso. An independent researcher, blinded to the interviewer's records, listened to the 12 audiotaped interviews and hand-recorded the carers' responses; for the symptoms questions (box 1) these showed 98.8\% agreement with the interviewer's original records. All analyses were carried out using Statistical Package for the Social Sciences (SPSS) V.14.

\section{RESULTS}

\section{Participants}

Carers of 325 children were invited to take part in the interview study, and $117(36.0 \%)$ agreed. Twelve respondents $(3.7 \%)$ could not be contacted subsequently and $26(8.0 \%)$ had no evidence of pneumonia in the radiologist's report, leaving 79 (24.3\%) eligible participants.
There was no significant difference between participants and non-participants in terms of the child's age, gender or diagnosis at the time of invitation ( $p>0.4$ for each). Twenty-two $(27.8 \%)$ participating children had a pleural effusion, including 12 (15.2\%) with a principal discharge diagnosis of empyema. Interviews were conducted face-to-face with the carer in hospital in 8/79 (10.1\%) cases, while the remaining interviews were conducted by telephone after discharge from hospital, a median of 21 days after hospital presentation. There were 43 children aged 3 or more years and 36 children aged under 3 years. The median age of children was 3.6 years (IQR 1.5-7.7 years), $52(65.8 \%)$ were male and $73(92.4 \%)$ were of white ethnicity. According to hospital records, 51 $(64.6 \%)$ cases were referred by a GP, $24(30.4 \%)$ cases presented to the Accident and Emergency (A\&E) department, and data were missing in four cases $(5.1 \%)$. Seventy-four (93.7\%) children were admitted to hospital after the initial assessment. The median duration of hospital stay was 2 days (IQR 1-4 days) and there were no deaths.

\section{First and later symptoms volunteered in the interview}

Carers first noticed that their child 'wasn't completely well' a median of 4 days (IQR 2-9 days) before the index hospital presentation. Fever was the most common symptom reported (table 1). Cough and 'cold' were common first symptoms, although 19/67 (28.4\%) carers who reported the presence of cough when prompted by the interviewer said it had started several days, weeks or even months before the date of illness onset stated in the questionnaire; they had not perceived their child as being unwell until the onset of more severe or systemic symptoms. Difficult or rapid

Table 1 Top 10 most common first and later symptoms volunteered in the interview, ranked by frequency ( $\mathrm{N}=79$ )

\begin{tabular}{|c|c|c|c|c|c|c|}
\hline & First symptom & $\mathbf{N}(\%)$ & Later symptom & $\mathbf{N}(\%)$ & $\begin{array}{l}\text { First and/or later } \\
\text { symptom }\end{array}$ & N (\%) \\
\hline 1 & $\begin{array}{l}\text { Fever or feverish } \\
\text { symptoms }\end{array}$ & $38(48.1)$ & $\begin{array}{l}\text { Fever or feverish symptoms } \\
\text { (new) }\end{array}$ & $32(40.5)$ & Fever or feverish symptoms & $66(83.5)$ \\
\hline 2 & Cough & $33(41.8)$ & Lethargic, tired or listless & $29(36.7)$ & Cough & $45(57.0)$ \\
\hline 3 & 'Cold' symptoms & $23(29.1)$ & $\begin{array}{l}\text { Difficult or rapid breathing } \\
\text { or shortness of breath }\end{array}$ & $23(29.1)$ & Lethargic, tired or listless & $44(55.7)$ \\
\hline 4 & Lethargic, tired or listless & $20(25.3)$ & Pain in torso & $20(25.3)$ & Vomiting & $29(36.7)$ \\
\hline 5 & Vomiting & $13(16.5)$ & Reduced feeding & $18(22.8)$ & $\begin{array}{l}\text { Difficult or rapid breathing } \\
\text { or shortness of breath }\end{array}$ & $28(35.4)$ \\
\hline 6 & Reduced feeding & $8(10.1)$ & Vomiting & $17(21.5)$ & Pain in torso & $25(31.6)$ \\
\hline 7 & 'Not himself/herself' & $7(8.9)$ & $\begin{array}{l}\text { Change in skin appearance } \\
\text { or colour* }\end{array}$ & $14(17.7)$ & 'Cold' symptoms & $24(30.4)$ \\
\hline 8 & $\begin{array}{l}\text { Difficult or rapid breathing } \\
\text { or shortness of breath }\end{array}$ & $6(7.6)$ & Cough (new) & $12(15.2)$ & $\begin{array}{l}\text { Change in skin appearance } \\
\text { or colour* }\end{array}$ & $17(21.5)$ \\
\hline 9 & Irritable & $6(7.6)$ & $\begin{array}{l}\text { Fever or feverish symptoms } \\
\text { worsened }\end{array}$ & $7(8.9)$ & Other pain $†$ & 9 (11.4) \\
\hline 10 & Pain in torso & $5(6.3)$ & $\begin{array}{l}\text { Cough changed or } \\
\text { worsened }\end{array}$ & 7 (8.9) & Irritable & $8(10.1)$ \\
\hline
\end{tabular}


Table 2 Symptoms volunteered as unusual and particularly concerning in the interview by at least $10 \%$ of carers in one or both age groups $(\mathrm{N}=79)$

\begin{tabular}{llrr}
\hline Response category & All ages (N=79) & Age <3 years (N=36) & Age 3+ years (N=43) \\
\hline High fever or feverish symptoms & $24(30.4 \%)$ & $12(33.3 \%)$ & $12(27.9 \%)$ \\
Difficult or rapid breathing or shortness of breath & $21(26.6 \%)$ & $12(33.3 \%)$ & $9(20.9 \%)$ \\
Pain in torsot & $17(21.5 \%)$ & $2(5.6 \%)$ & $15(34.9 \%)$ \\
Persistent fever or fever not affected by antipyretics & $15(19.0 \%)$ & $6(16.7 \%)$ & $9(20.9 \%)$ \\
Lethargic, tired or listless & $10(12.7 \%)$ & $3(8.3 \%)$ & $7(16.3 \%)$ \\
Distressed or screaming/inconsolable & $8(10.1 \%)$ & $4(11.1 \%)$ & $4(9.3 \%)$ \\
Rapid deterioration (general) & $8(10.1 \%)$ & $4(11.1 \%)$ & $4(9.3 \%)$ \\
Lifeless, unresponsive, drowsy or floppy & $7(8.9 \%)$ & $5(13.9 \%)$ & $2(4.7 \%)$ \\
Reduced feeding or not feeding & $7(8.9 \%)$ & $4(11.1 \%)$ & $3(7.0 \%)$ \\
Persistent symptoms (general) & $7(8.9 \%)$ & $4(11.1 \%)$ & $3(7.0 \%)$ \\
\hline
\end{tabular}

*Included shaking, sweating and feeling 'hot and cold'.

†Significant difference in proportions between age groups $(p<0.01)$.

breathing, pain in the torso and a change in skin colour or appearance were almost exclusively reported as later symptoms.

\section{Symptoms volunteered as unusual and particularly concerning to carers}

Carers cited something 'unusual' about the index illness which had particularly concerned them in $75 / 79$ $(94.9 \%)$ cases. These were mostly non-specific physical symptoms such as high fever, or behavioural changes such as lethargy, distress or reduced feeding (table 2). Carers often referred to previous illnesses in responding to this question. Pain in the torso was commonly cited by carers of children aged over 3 years, but rarely in children aged under 3 years, a difference which was statistically significant (table 2). No single symptom was cited by more than $50 \%$ of carers. Difficult or rapid breathing or shortness of breath was the only respiratory symptom cited by more than 5\% of carers. In contrast, the absence of usual respiratory symptoms ('cold' symptoms, cough, 'chesty' symptoms or wheeze) was identified as a cause for concern by four $(5.1 \%)$ carers.

\section{Difficult or rapid breathing}

'Rapid, shallow breathing or panting' was reported by 69 $(87.3 \%)$ carers when prompted by the interviewer, beginning a median of 2 days (IQR 1-6 days) after illness onset. Only $21(30.4 \%)$ of these 69 carers cited breathing symptoms as a cause for particular concern. Five carers $(6.3 \%)$ volunteered that they had failed to recognise the importance of these symptoms. Another five carers $(6.3 \%)$ spontaneously reported possible misjudgement of breathing symptoms by clinicians, including GPs and emergency physicians (table 3).

Table 3 Evidence of possible misinterpretation of breathing symptoms by carers and clinicians, spontaneously reported by interviewed carers

\begin{tabular}{|c|c|c|}
\hline \multicolumn{2}{|c|}{$\begin{array}{l}\text { Radiological } \\
\text { diagnosis and study } \\
\text { ID number }\end{array}$} & \multirow{2}{*}{$\begin{array}{l}\text { Possible misjudgement } \\
\text { Carer thought child seemed 'a bit out of breath' but did not seek medical advice until child seemed } \\
\text { very distressed the following day }\end{array}$} \\
\hline 1 & $\begin{array}{l}\text { Pleural effusion } \\
\text { (114) }\end{array}$ & \\
\hline 2 & Empyema (145) & Carer delayed seeking medical advice because they presumed breathing symptoms were due to \\
\hline 3 & Empyema (161) & asthma \\
\hline 4 & Pneumonia (195) & As above \\
\hline 5 & Pneumonia (234) & As above \\
\hline 6 & Pneumonia (123) & A\&E doctor said child's chest was clear and attributed rapid breathing to high temperature \\
\hline 7 & Empyema (159) & $\begin{array}{l}\text { Staff in paediatric assessment unit attributed shortness of breath to asthma and sent child home } \\
\text { with an inhaler }\end{array}$ \\
\hline 8 & Pneumonia (169) & $\begin{array}{l}\text { Carer was concerned that child had laboured breathing at night. One GP attributed this to a viral } \\
\text { infection and advised carer to continue giving Calpol; another said child's chest was clear and sent } \\
\text { them home }\end{array}$ \\
\hline 9 & $\begin{array}{l}\text { Pleural effusion } \\
\text { (239) }\end{array}$ & GP attributed shortness of breath to hayfever \\
\hline 10 & Pneumonia (250) & GP did not address carer's concern about child's panting and asked child 'why he was doing that' \\
\hline
\end{tabular}


Pain in children aged 3 years and over

According to carers, when prompted by the interviewer (box 1-item 3), 36/43 (83.7\%) children aged 3 years and over complained of pain in the torso (including all 12 children with pleural effusion or empyema), 23 $(53.5 \%)$ complained of a headache and $12(27.9 \%)$ complained of general aching. Pain in the torso began a median of 1.5 days after illness onset (IQR $1-5$ days) and was usually located in the chest and/or abdomen (19 children each; $44.2 \%$ ). Complaints of pain in the back $(15 / 43 ; 34.9 \%)$, side $(10 / 43 ; 23.3 \%)$ and shoulder (6/ $43 ; 14.0 \%)$ were also reported. Among those who complained of pain in the torso, the 12 children with pleural effusion or empyema experienced a significantly longer delay between the onset of pain and index hospital presentation than the 24 children with uncomplicated pneumonia (median 3 days vs 1 day; IQR $1.5-5$ days vs $0-$ 1.5 days $)(\mathrm{p}=0.01)$. Pain at other sites was reported in 14 children aged 3 or more years: $8(18.6 \%)$ with pain in the legs, $4(9.3 \%)$ with neck pain and $2(4.7 \%)$ with pain in one arm. Evidence of possible misjudgement of torso pain by clinicians, including GPs and emergency physicians, was spontaneously reported by six $(14.0 \%)$ carers of children in this age group, and misjudgement of pain by carers themselves was volunteered in two $(4.7 \%)$ cases (table 4). The majority of these children were ultimately diagnosed with empyema or pleural effusion.

\section{DISCUSSION}

Our interviews provide a novel insight into carers' accounts of their children's symptoms and evidence of possible failure to recognise the signs of serious infection by carers and clinicians.
Almost all carers reported something unusual about the illness which had particularly concerned them, mostly non-specific physical symptoms such as high fever, or behavioural changes such as lethargy, distress or reduced feeding. Pain in the torso was common in children aged 3 or more years, reported by more than $80 \%$ of carers and cited as the main cause for carer concern. In addition to the chest, other common sites of pain were the abdomen, side, back, shoulder and legs. Compared to children with uncomplicated pneumonia, those with pleural effusion or empyema experienced a significantly longer delay between the onset of torso pain and hospital presentation. Some carers provided evidence of possible misinterpretation of pain and breathing symptoms by clinicians prior to the index hospital presentation.

This study recruited cases from several hospitals in urban and rural locations. Data were collected directly from carers rather than from medical records and the purpose-designed interview schedule enabled us to elicit rich and detailed information. Carers were invited to talk openly and in depth about their children's symptoms, using their own terminology. Such discussion would rarely be possible during time-restricted medical consultations, so provided an opportunity to identify symptoms and illness characteristics of importance to carers rather than clinicians.

Nevertheless, our study has several limitations. First, our case series is only a small sample of the study population and is unlikely to represent the whole clinical spectrum of severity of childhood pneumonia presenting to hospital. The high prevalence of empyema, effusion and hospital admission in our sample strongly suggests that severe pneumonia is over-represented; this is probably due to an

Table 4 Evidence of possible misinterpretation of pain by carers and clinicians, spontaneously volunteered by interviewed carers

\begin{tabular}{|c|c|c|c|}
\hline \multicolumn{2}{|c|}{ Site of pain } & \multirow{2}{*}{$\begin{array}{l}\text { Radiological diagnosis and } \\
\text { study ID number } \\
\text { Empyema (161) }\end{array}$} & \multirow{2}{*}{$\begin{array}{l}\text { Possible misjudgement } \\
\text { Carer assumed child had pulled a muscle doing fitness exercises in a } \\
\text { sports class, so did not seek medical attention initially }\end{array}$} \\
\hline 1 & Abdomen & & \\
\hline 2 & Abdomen & Pleural effusion (212) & $\begin{array}{l}\text { Carer thought this was due to 'muscle strain from coughing', so did not } \\
\text { seek medical attention initially }\end{array}$ \\
\hline 3 & Abdomen & Empyema (174) & $\begin{array}{l}\text { Staff in paediatric assessment unit said pain was 'probably due to } \\
\text { coughing'. No chest } x \text {-ray was done }\end{array}$ \\
\hline 4 & $\begin{array}{l}\text { Back and } \\
\text { abdomen }\end{array}$ & Empyema (210) & $\begin{array}{l}\text { GP diagnosed a chest infection and prescribed antibiotics. Carer } \\
\text { phoned GP } 2 \text { days later due to child's deteriorating condition but GP } \\
\text { refused to see child due to unfinished course of antibiotics }\end{array}$ \\
\hline 5 & Back & Empyema (201) & $\begin{array}{l}\text { On two consecutive visits to a paediatric assessment unit, clinician said } \\
\text { pain was because child had 'torn a muscle'. No chest } x \text {-rays were done }\end{array}$ \\
\hline 6 & $\begin{array}{l}\text { Chest and } \\
\text { back }\end{array}$ & Empyema (159) & $\begin{array}{l}\text { A\&E doctor could not find cause of pain and sent child home without } \\
\text { antibiotics }\end{array}$ \\
\hline 7 & Side & Pneumonia (170) & $\begin{array}{l}\text { GP said pain was probably due to 'muscle strain from coughing' during } \\
\text { phone consultation with mother }\end{array}$ \\
\hline 8 & Side & Pneumonia (271) & $\begin{array}{l}\text { GP diagnosed influenza and said pain was due to 'coughing pulling on } \\
\text { muscles' and 'hunger' }\end{array}$ \\
\hline
\end{tabular}


increased likelihood of invitation for cases with a longer stay in hospital and/or greater motivation of these carers to participate in the study. Furthermore, mild or unusual presentations may not have had a chest x-ray and thus not met our case definition. Second, data were collected retrospectively from carers and therefore may be prone to recall bias. To minimise this, interviews were carried out as soon as possible, but memory decay may have led to underestimation of the frequency of some symptoms. Finally, the absence of a comparison group precluded any estimation of the sensitivity and specificity of symptoms for radiographic pneumonia.

Whether a carer recognises illness in their child largely depends on what they consider 'normal' for their child, especially changes in behaviour such as eating and sleeping. ${ }^{20}$ In a qualitative study of 12 Samoan children admitted to hospital with pneumonia in New Zealand, carers described the illness as more serious than previous non-urgent illnesses, explaining this in terms of physical changes (most commonly breathing changes and fever) and behavioural changes such as lethargy and poor feeding. ${ }^{21}$ Similar changes were causes for concern to carers in our study. However, the small proportion of carers who reported concerns about difficult breathing or shortness of breath suggests that some may not have recognised this as a sign of serious infection. This is consistent with a qualitative study in Wales of children admitted with complicated respiratory infections (including pneumonia and empyema) which found that some carers failed to act immediately on recognition of altered breathing symptoms. ${ }^{22}$

Other case series in Europe have reported chest or abdominal pain in a minority of cases, ${ }^{12} 16$ but data were collected retrospectively from hospital records, without knowledge of whether or not clinicians had asked carers and children about pain. Carers may not necessarily volunteer this symptom, especially if they do not associate it with their child's illness or if it has been previously dismissed by a clinician, as found in our case series. Blacklock et $a l^{17}$ found that abdominal pain reported by parents was not a reliable predictor of serious respiratory infection, but their comparison group contained children with non-specific abdominal pain, gastrointestinal infections and urinary tract infections presenting to hospital. Abdominal pain, and other pain in the torso, may be a more useful discriminator among children with respiratory infections in primary care. Severe abdominal pain with fever, but absent or minimal respiratory symptoms or signs, has been highlighted in pneumonia before, ${ }^{23}$ and acute abdominal pain has sometimes led to delayed diagnosis and even laparotomy. ${ }^{24}$ Pain in one arm was also emphasised in a recent case report. ${ }^{25}$ Our findings suggest that chest and abdominal pain, referred pain at other sites, and even pain in the legs, may be more common than expected, and may not always be interpreted correctly by clinicians.

The confidential enquiry into child deaths in the UK demonstrated that misinterpretation of the symptoms of serious infection in primary care can have tragic consequences. ${ }^{14}$ Carefully eliciting the carer's reports of illness history, symptoms of particular concern and the perception that the illness is 'different' from previous illnesses may alert the clinician to the possibility of a more serious respiratory infection. Pain in the torso (including the abdomen, back, shoulder and side) may be a common symptom of pneumonia in children aged 3 or more years. Carers of children presenting in primary care with a respiratory infection could be encouraged to re-consult if their child develops pain in the torso or rapid or difficult breathing, as these symptoms were not always recognised as serious by carers in our study. Raising awareness about the importance of these symptoms might also help to address the knowledge gap. Blacklock et al ${ }^{17}$ cast doubt on the value of carer-reported symptoms in recognising serious respiratory infection in hospitals, but this has not been confirmed in primary care. There is therefore a need for further research into the potential value of the carer's perspective in identifying serious respiratory infection in primary care. A recent study by Haj-Hassan $e t a l^{26}$ estimated the diagnostic value of presenting symptoms in primary care for meningococcal disease, the findings of which have important implications for telephone and face-to-face triage. A similar study of the diagnostic value of carer-reported and presenting symptoms in primary care for serious respiratory infection would be extremely valuable.

\section{CONCLUSION}

Pain in the torso and carer concerns about unusual symptoms in their children may provide valuable additional information in a clinician's assessment of the risk of pneumonia in primary and secondary care. A larger, prospective study is needed to confirm the diagnostic value of these features.

Acknowledgements We are very grateful to the following people: all carers and children who took part in the study; all clinicians who kindly recruited patients for the study; Lead Collaborators Dr Anjum Gandhi and Dr lan Hodges (Royal Glamorgan Hospital), Dr David Deekollu (Prince Charles Hospital), Dr Kate Creese and Dr Nirupa D'Souza (Princess of Wales Hospital), Dr Marcus Pierrepoint and Dr Yvette Cloete (Nevill Hall Hospital), Dr Michelle Barber (Royal Gwent Hospital) and Dr Rachel Evans (Morriston Hospital); Ann Russell, Anwen Howells and Marie Williams at the NISCHR Clinical Research Centre for helping to collect medical data; and Hayley Prout at Cardiff University for providing an independent quality assessment of interview records.

Contributors All authors contributed to the planning, management, interpretation and reporting of this work. JCC collected and analysed data under the supervision of CCB, CVE, MRE and KH.

Funding This study was supported by the Medical Research Council as part of a PhD Studentship (grant number G0600288); the British Society for Antimicrobial Chemotherapy (grant number GA854); and the South East Wales Trials Unit and Wales School for Primary Care Research, both funded by the National Institute for Social Care and Health Research (NISCHR), Welsh Government.

Competing interests None.

Ethics approval The study was approved by the Research Ethics Committee for Wales (Ref. 08/MRE09/45). 
Provenance and peer review Not commissioned; externally peer reviewed.

Data sharing Statement No additional data available.

\section{REFERENCES}

1. Farha $\mathrm{T}$, Thomson $\mathrm{AH}$. The burden of pneumonia in children in the developed world. Paediatr Respir Rev 2005;6:76-82.

2. Thomson A. $2010 / 11$ Paediatric pneumonia audit. 2011. http://www. brit-thoracic.org.uk/audit.aspx (accessed 16 May 2012).

3. Lee GE, Lorch SA, Sheffler-Collins S, et al. National hospitalization trends for pediatric pneumonia and associated complications. Pediatrics 2010;126:204-13.

4. Koshy E, Murray J, Bottle A, et al. Impact of the seven-valent pneumococcal conjugate vaccination (PCV7) programme on childhood hospital admissions for bacterial pneumonia and empyema in England: national time-trends study, 1997-2008. Thorax 2010;65:770-4.

5. Roxburgh CS, Youngson GG, Townend JA, et al. Trends in pneumonia and empyema in Scottish children in the past 25 years. Arch Dis Child 2008:93:316-18.

6. Grijalva CG, Nuorti JP, Zhu Y, et al. Increasing incidence of empyema complicating childhood community-acquired pneumonia in the United States. Clin Infect Dis 2010;50:805-13.

7. Strachan R, Jaffe A. Assessment of the burden of paediatric empyema in Australia. J Paediatr Child Health 2009;45:431-6.

8. Finley C, Clifton J, FitzGerald JM, et al. Empyema: an increasing concern in Canada. Can Respir J 2008;15:85-9.

9. Francois $\mathrm{P}$, Desrumaux $\mathrm{A}$, Cans $\mathrm{C}$, et al. Prevalence and risk factors of suppurative complications in children with pneumonia. Acta Paediatr 2010;99:861-6.

10. Van Ackere T, Proesmans M, Vermeulen F, et al. Complicated parapneumonic effusion in Belgian children: increased occurrence before routine pneumococcal vaccine implementation. Eur J Pediatr 2009;168:51-8.

11. Goldbart AD, Leibovitz E, Porat N, et al. Complicated community acquired pneumonia in children prior to the introduction of the pneumococcal conjugated vaccine. Scand J Infect Dis 2009;41:182-7.

12. Juven T, Ruuskanen O, Mertsola J. Symptoms and signs of community-acquired pneumonia in children. Scand $J$ Primary Health Care 2003;21:52-6.
13. Shah S, Mathews B, Neuman Ml, et al. Detection of occult pneumonia in a pediatric emergency department. Pediatr Emerg Care 2010;26:615-21.

14. Harnden A, Mayon-White R, Mant D, et al. Child deaths: confidential enquiry into the role and quality of UK primary care. Br J Gen Pract 2009;59:819-24.

15. Buntinx F, Mant $D$, Van den Bruel A, et al. Dealing with low-incidence serious diseases in general practice. $\mathrm{Br} J$ Gen Pract 2011;61:43-6.

16. Korppi $M$, Don $M$, Valent $F$, et al. The value of clinical features in differentiating between viral, pneumococcal and atypical bacterial pneumonia in children. Acta Paediatr 2008:97:943-7.

17. Blacklock C, Mayon-White R, Coad N, et al. Which symptoms and clinical features correctly identify serious respiratory infection in children attending a paediatric assessment unit? Arch Dis Child 2011;96:708-14.

18. Van den Bruel A, Aertgeerts B, Bruyninckx R, et al. Signs and symptoms for diagnosis of serious infections in children: a prospective study in primary care. Br J Gen Pract 2007;57:538-46.

19. Van den Bruel A, Haj-Hassan T, Thompson M, et al. Diagnostic value of clinical features at presentation to identify serious infection in children in developed countries: a systematic review. Lancet 2010;375:834-45.

20. Irvine S, Cunningham-Burley S. Mothers' concepts of normality, behavioural change and illness in their children. Br J Gen Pract 1991;41:371-4.

21. Young N. The pre-hospital experiences of Samoan families who have had a child admitted to hospital with pneumonia: a qualitative investigation. Pac Health Dialog 2001;8:20-8.

22. Francis NA, Crocker JC, Gamper A, et al. Missed opportunities for earlier treatment? A qualitative interview study with parents of children admitted to hospital with serious respiratory tract infections. Arch Dis Child 2011;96:154-9.

23. Kanegaye JT, Harley JR. Pneumonia in unexpected locations: an occult cause of pediatric abdominal pain. J Emerg Med 1995;13:773-9.

24. Ravichandran D, Burge DM. Pneumonia presenting with acute abdominal pain in children. Br J Surg 1996;83:1707-8.

25. Bechtel K, Siew L. Arm pain and fever as an unusual presentation of lobar pneumonia in a 3-year-old girl: case report. Pediatr Emerg Care 2011;27:420-1.

26. Haj-Hassan TA, Thompson MJ, Mayon-White RT, et al. Which early 'red flag' symptoms identify children with meningococcal disease in primary care? Br J Gen Pract 2011;61:e97-104. 